\title{
PESSOAS COM DEFICIÊNCIA MENTAL OU INTELECTUAL: UM ESTUDO SOBRE CASAMENTO E UNIÃO ESTÁVEL NA PERSPECTIVA DA LEI BRASILEIRA DE INCLUSÃO
}

\author{
PEOPLE WITH MENTAL OR INTELLECTUAL DISABILITIES: \\ A STUDY ON MARRIAGE AND STABLE UNION IN THE PERSPECTIVE OF THE \\ BRAZILIAN LAW OF INCLUSION
}

\author{
PERSONAS CON DISCAPACIDAD MENTAL O INTELECTUAL: \\ UN ESTUDIO SOBRE EL MATRIMONIO Y LA UNIÓN ESTABLE EN LA \\ PERSPECTIVA DE LA LEY BRASILEÑA DE INCUSIÓN
}

\begin{abstract}
MARCElo Pereira dos Santos
http://orcid.org/0000-0002-2622-1923 / http://lattes.cnpq.br/5276756160691614 / marcelo.pereira.adm.ufrrj@gmail.com Universidade Estácio de Sá Rio de Janeiro, RJ, Brasil.
\end{abstract}

\section{EdNA RAQUel RodRIgUes SANTOS HOgEMANN} http://orcid.org/0000-0002-6274-0026 / http://lattes.cnpq.br/7074003578919112 / mfrepoles@ufmg.br Universidade Estácio de Sá; Universidade do Grande Rio; Universidade Federal do Estado do Rio de Janeiro. Rio de Janeiro, RJ, Brasil.

\begin{abstract}
RESUMO
Este trabalho tem por objeto a legitimidade do casamento civil e união estável de pessoas com deficiência mental ou intelectual, tomando como referencial a Lei Brasileira de Inclusão, o princípio da intervenção mínima nas relações de família e os limites da curatela. 0 artigo tem por escopo compreender a delimitação da extensão legal em torno da vontade declarada por curadores, responsáveis e apoiadores, diante dos preceitos descritos nos artigos 1.513, 1.550, $\$ 2^{\circ}$, do Código Civil, artigo 755, caput e parágrafos, do Código de Processo Civil. Para tanto, é empregada a metodologia dialético-descritiva e explicativa, fundada no estudo das variáveis apontadas pela doutrina, legislação e jurisprudência, além da reflexão sobre a evolução do pensamento em torno dos requisitos de existência, validade e eficácia do matrimônio e os pactos de convivências registrados no cartório de pessoas naturais.
\end{abstract}

Palavras-chave: Capacidade civil; Casamento; Família; Inclusão; União estável.

\section{ABSTRACT}

This work is subject to the legitimacy of civil marriage and the stable union of people with mental or intellectual disabilities, taking as references the Brazilian inclusion law, the principle of minimal intervention in family relationships and the boundaries of curatorship. The article is scoped to understand the demarcation of the legal extent around the will declared by curators, responsible and supporters, in front of the precepts described in articles 1513, 1550, §2nd, of the Civil Code, article 755, caput and paragraphs of the Code of Civil Procedure. For this, it is employed the methodology dialectical-descriptive and explanatory, founded in the study of the variables pointed out by doctrine, legislation and jurisprudence, in addition to reflection on the evolution of thought around the requirements of existence, validity and effectiveness of matrimony and the pacts of coexistences recorded in the registry of natural people.

Keywords: Civilian capacity; Wedding; Family; Inclusion; Stable union. 
PESSOA COM DEFICIÊNCIA MENTAL OU INTELECTUAL: UM ESTUDO SOBRE CASAMENTO E UNIÃO ESTÁVEL NA PERSPECTIVA DA LEI BRASILEIRA DE INCLUSÃO

MARCELO PEREIRA dos SANTOS EdNA RAQUEL RODRIGUES SANTOS HOGEMANN

\section{RESUMEN}

Este trabajo es objeto de la legitimidad del matrimonio civil y de la unión estable de las personas con discapacidad mental o intelectual, tomando como referencia la ley de inclusión brasileña, el principio de intervención mínima en las relaciones familiares y los limites de la tutela. El artículo tiene el ámbito de entender la demarcatión de la extensión jurídica en torno a la voluntad declarada por curadores, guardianes y simpatizantes, antes de los preceptos descritos en los artículos 1.513, 1.550, § 2, del Código Civil, artículo 755, cabeza y párrafos, del Código de Procedimiento Civil. Para ello se emplea la metodologia dialética-descriptiva y explicativa, fundada en el estúdio de las variables señaladas por la doctrina, la legistación y la jurisprudência, además de la reflexión sobre la evolución del pensamento en torno a los requerimentos de existencia, validez y efectividad del matrimonio y los convênios de convivencia registrados en el notário de las personas físicas.

Palabras clave: Capacidad civil; Boda familia; Inserción; Unión estable.

\section{SUMÁRIO}

INTRODUÇÃO; 1 CASAMENTO, UNIÃO ESTÁVEL, FAMÍLIA, INCLUSÃO E DIGNIDADE HUMANA: UMA RELAÇÃO INDISSOCIÁVEL; 2. VONTADE DECLARADA E VONTADE TRADUZIDA; 3. EXISTÊNCIA, VALIDADE E EFICÁCIA DO CASAMENTO DA PESSOA COM DEFICIÊNCIA MENTAL OU INTELECTUAL NA FORMA DA LEI BRASILEIRA DE INCLUSÃO; 4. VONTADE TRADUZIDA E PACTO ANTINUPCIAL; CONCLUSÃO; REFERÊNCIAS.

\section{INTRODUÇÃO}

Um dos maiores avanços da ordem jurídica contemporânea se deu com a Lei $\mathrm{n}^{\circ}$ 13.146/2015, norma intitulada como “Lei Brasileira de Inclusão" (LBI), regra de extensão constitucional que afastou o parâmetro médico em torno da capacidade civil da pessoa natural, instituindo como referencial o princípio da dignidade humana, conforme disposição do Decreto Legislativo $\mathrm{n}^{\circ} 186$ de 2008 que aprovou a Convenção sobre os direitos da pessoa com deficiência, assinada em Nova lorque, no dia 30 de março de 2007, consagrando o propósito da comunidade mundial quanto à superação das barreiras impeditivas da participação plena do cidadão nas decisões da vida privada e nas escolhas públicas.

Essa mudança causou impactos no Direito de Família, em especial, nos requisitos de existência, validade e eficácia do casamento, pois pessoas com deficiência mental que estavam impossibilitadas de casar ou constituir união estável, a partir de 6 de janeiro de 2016 (após o período de vacatio legis), passaram a ter o direito de constituir novos núcleos de relacionamento com reconhecimento do Estado e da sociedade.

Apesar da clara finalidade da norma de extensão constitucional, o problema a ser enfrentado pela doutrina e pelos tribunais brasileiros refere-se ao caso de pessoas que já haviam sido interditadas e hoje dão início ao procedimento de habilitação para casamento ou 
PESSOA COM DEFICIÊNCIA MENTAL OU INTELECTUAL: UM ESTUDO SOBRE CASAMENTO E UNIÃO ESTÁVEL NA PERSPECTIVA DA LEI BRASILEIRA DE INCLUSÃO

MARCELO PEREIRA dos SANTOS EdNA RAQUEL RODRIGUES SANTOS HOGEMANN

formalização de união estável, por iniciativa de seus curadores ou apoiadores. Assim sendo, são postas em questão uma série de dúvidas, capazes de impedir a eficácia social e jurídica da Lei Brasileira de Inclusão, tais como: I. Pessoas com deficiência mental ou intelectual, impossibilitadas de exteriorizar vontade poderiam firmar pacto antenupcial por intermédio de curadores ou seus responsáveis? II. A vontade traduzida estaria inserida no conceito de declaração para a teoria dos negócios jurídicos? III. Os tabeliães ou registradores teriam responsabilidade pela ausência de diligência quanto ao procedimento de habilitação para o casamento ou registro de união estável? IV. Como mensurar se a escolha do cônjuge ou companheiro foi fruto da vontade da pessoa com deficiência mental ou intelectual? V. Os poderes da curatela abarcariam a escolha do regime de bens?

Os questionamentos mencionados acima são dotados de relevância jurídica, porque visam estabelecer a delimitação normativa, sob a perspectiva constitucional, do casamento e da união estável pretendida pelas pessoas com deficiência, sem possibilidade de exprimir suas vontades, ou que venham se valer da atuação do curador ou responsável. Ademais, a ausência de balizas normativas pode dar ensejo à insegurança jurídica e colocar em risco os interesses das pessoas relativamente capazes nos termos da LBI.

Este trabalho não tem o objetivo de conduzir ao esvaziamento do direito de constituir família por intermédio do casamento ou da união estável das pessoas com deficiência, mas sim delimitar a extensão legal da vontade declarada por curadores e apoiadores, diante dos preceitos descritos nos artigos 1.513, 1.550, \$2 ${ }^{\circ}$ e artigo 1.772 , caput e parágrafo único, do Código Civil de 2002.

Na primeira parte, é dado destaque a relação existente entre a formação das famílias e sua relevância para consolidação da dignidade humana, haja vista, a influência das relações de afeto e a integração com a sociedade do individuo pertencente à célula que compõe todo o corpo orgânico de uma comunidade cidadã dentro da compreensão de Estado democrático de Direito, tal como a sofisticação dos direitos inerentes às pessoas com deficiência por intermédio da Lei Brasileira de Inclusão e da Convenção de Nova York1, integrados à ordem jurídica nacional com status de emenda constitucional.

1 Convenção de Nova York é a denominação dada à Convenção das Nações Unidas sobre os Direitos das Pessoas com Deficiência, assinada em Nova York, no dia 30 de março de 2007, a qual ingressou no ordenamento jurídico brasileiro por força do Decreto Legislativo $n^{\circ} 186$, de 9 de julho de 2008 , conforme procedimento do $\S 3^{\circ}$, do artigo $5^{\circ}$, da Constituição, bem como do Decreto $n^{\circ} 6.949$, de 25 de agosto de 2009. Essa norma ganha relevância por se tornar um marco histórico para o constitucionalismo brasileiro, porque é a primeira convenção internacional de direitos humanos, reconhecida no Brasil, equivalente às 
PESSOA COM DEFICIÊNCIA MENTAL OU INTELECTUAL: UM ESTUDO SOBRE CASAMENTO E UNIÃO ESTÁVEL NA PERSPECTIVA DA LEI BRASILEIRA DE INCLUSÃO

MARCELO PEREIRA dos SANTOS EdNA RAQUEL RODRIGUES SANTOS HOGEMANN

Em seguida, traça-se um paralelo entre as formas de expressão da vontade, dano ênfase à tradução das escolhas da pessoa com deficiência mental ou intelectual, de acordo com a interpretação dos curadores e respectivos responsáveis. Por outro lado, é feita uma descrição crítica sobre o exercício da autonomia privada, sob a ótica da Lei Brasileira de Inclusão, em conjunto com os parâmetros constitucionais e normas internacionais, que regem a matéria, a fim de estancar as dúvidas referentes à eficácia normativa do artigo 1.550, $\$ 2^{\circ}$, do Código Civil de 2002.

O terceiro tópico compreende os planos de existência, validade e eficácia em torno do casamento civil e da união estável realizados no Brasil, com base nas inovações legais introduzidas na ordem jurídica por intermédio da Lei $n^{\circ} 13.146 / 2015$. O ponto, que mais chama a atenção, está ancorado no elemento vontade e na capacidade civil das pessoas com deficiência, pois os negócios jurídicos que envolviam sujeitos com desenvolvimento mental incompleto eram passíveis de anulação ou nulidade, a depender do grau de comprometimento intelectual e cognitivo.

No item subsequente, sublinha-se os desdobramentos do pacto antinupcial firmado por pessoas com deficiência mental ou intelectual, descrevendo as consequências jurídicas decorrentes da vontade declarada através da tradução realizada por curadores e responsáveis, em prol dos interesses do casal. Outrossim, salienta-se a importância da postura diligente do tabelião quanto da lavratura da escritura pública, tal como a observância obrigatória dos princípios da boa-fé objetiva e da função social dos contratos. Além disso, sobreleva-se os efeitos patrimoniais do casamento e os aspectos relacionados à regra supletiva, prevista no artigo 1.640 , do CC/02.

Toda a temática é delineada de acordo com os princípios da dignidade humana e da mínima intervenção do Estado no interesse das famílias, corroborando com ideais de justiça erguidos pela Lei Brasileira de Inclusão para consagração do imperativo categórico, definido por Immanuel Kant2, que coloca o ser humano na base das relações sociais e jurídicas, independentemente de estereótipo, preconceito, qualificação ou classe econômica.

As reflexões postas aqui, não constituem respostas sobre as indagações difundidas no momento atual, mas sim, a busca por melhores perguntas que se adequem à realidade e aos

emendas constitucionais. Portanto, sua eficácia reforçada serve de parâmetro de controle para as regras supras legais e demais leis infraconstitucionais.

2 KANT, I. A Metafísica dos Costumes. Trad. de Edson Bini. 1 ed. Bauru: Edipro, 2003.

Revista Eletrônica do Curso de Direito da UFSM www.ufsm.br/revistadireito v. 13, n. 3 / 2018 p.904-926 
PESSOA COM DEFICIÊNCIA MENTAL OU INTELECTUAL: UM ESTUDO SOBRE CASAMENTO E UNIÃO ESTÁVEL NA PERSPECTIVA DA LEI BRASILEIRA DE INCLUSÃO

MARCELO PEREIRA dos SANTOS EDNA RAQUEL RODRIGUES SANTOS HOGEMANN

desafios enfrentados por todos aqueles que sofrem com a discriminação, isolamento e as agruras experimentas dia a dia, esvaziando, por completo, o individuo que é impedido de viver a vida com colorido, alegria, felicidade e afeto.

\section{CASAMENTO, UNIÃO ESTÁVEL, FAMÍLIA, INCLUSÃO E DIGNIDADE HUMANA: UMA RELAÇÃO INDISSOCIÁVEL}

Atualmente, discute-se a equiparação entre casamento e união estável, tomando com referência o artigo $226, \$ 3^{\circ}$, da Constituição da República de 1988 . A questão foi objeto do Recurso Extraordinário $n^{\circ}$ 878.694-MG, sob o qual o Supremo Tribunal Federal se manifestou pela repercussão geral da matéria. A Corte decidiu pela equiparação entre cônjuges e companheiros, ficando consignado no voto do Ministro Luís Roberto Barroso, que haveria um retrocesso no tratamento diferenciado em relação as duas espécies de família, circunstância que poderia gerar uma hierarquização não admitida na Carta Magna. O mérito tratava do direito sucessório dos conviventes e o tratamento distinto extraído do artigo 1.790, do Código Civil de 2002, que repercute na esfera patrimonial do(a) companheiro(a) sobrevivente, já que a lei reserva, apenas, um terço dos bens adquiridos de forma onerosa durante a convivência, destoando da regra aplicada aos cônjuges, que, além de serem herdeiros necessários, tem a garantia legal de não concorrer no direito de herança com os parentes colaterais, ou seja, irmãos, tios, sobrinhos, primos, tios-avôs e tias-avós.

Esse ponto é relevante para o estudo realizado sobre o objeto deste trabalho em razão das dúvidas relacionadas à convivência e patrimônio amealhado durante um lapso temporal que configura a comunhão de vida, voltada para consolidação de laços familiares. Ademais, o caráter ambíguo da norma constitucional leva o intérprete à conclusão, sob duas vertentes: a) entendese que o constituinte faz distinção entre união estável e casamento, já que este último é dotado de maior formalidade, inclusive exigindo solenidade dos atos, formalização do acordo quanto ao regime de bens e registro no respectivo órgão competente3; b) conclui-se que, o constituinte teve a intenção de equiparar o concubinato puro ao casamento, na ausência de impedimentos

3 No voto do Ministro Dias Toffoli, referente ao objeto do Recurso Extraordinário $n^{\circ}$ 878.694-MG, ficou consignada sua interpretação em torno do artigo 1.790, Código Civil, dispondo no seguinte sentido: "certo é que a norma civil apontada como inconstitucional não hierarquizou o casamento em relação à união estável, mas acentuou serem eles formas diversas de entidades familiares, nos exatos termos da exegese do artigo 226, parágrafo $3^{\circ}$, da Constituição Federal” (Disponível em: <http://www.stf.jus.br/arquivo/cms/noticiaNoticiaStf/anexo/RE878694.pdf>. Acesso em 30 abr. 2017). 
PESSOA COM DEFICIÊNCIA MENTAL OU INTELECTUAL: UM ESTUDO SOBRE CASAMENTO E UNIÃO ESTÁVEL NA PERSPECTIVA DA LEI BRASILEIRA DE INCLUSÃO

MARCELO PEREIRA dos SANTOS EdNA RAQUEL ROdRIGUES SANTOS HOGEMANN

legais, pois a Declaração Universal de Direitos Humanos ressalta no seu artigo XVI, item 3, que "a família é o núcleo natural fundamental da sociedade e tem direito à proteção da sociedade e do Estado"4.

Muito mais importante do que discutir as peculiaridades do casamento e da união estável, empreende-se o máximo esforço cognitivo sobre o texto constitucional de compreender a dimensão da família na sociedade contemporânea. Nela estão os valores, que edificam a pessoa humana e se constrói a concepção de mundo, identificando a diferença entre o certo e o errado; aprendendo as distâncias entre o bem e o mal; assimilando a importância do afeto; concebendo o indivíduo como cidadão; integrado a um corpo social complexo; e desenhando as fronteiras, que dividem direitos e deveres, de acordo com o ordenamento jurídico vigente. Significa dizer que, a o núcleo familiar é o principal ambiente que viabiliza o arvorecer da vida com dignidade.

A partir da família, a pessoa passa a criar sua própria trajetória e ampliar o número de bifurcações que podem levá-la ao alcance da felicidade, assim como ao cumprimento de suas metas e objetivos enquanto puder eleger aquilo que entende de mais importante. Para tanto, não importaria deliberar sobre as relações constituídas através de procedimentos formais e solenes e aquelas destituídas de ratificação do Estado, tendo em conta o princípio da mínima intervenção sobre a comunhão de vida instituída pela família.

O materialismo sistêmico e o apego aos efeitos patrimoniais decorrentes da formação dos vínculos familiares são os principais obstáculos, que inviabilizam a transcendência da norma constitucional e legal quanto ao tratamento jurídico equivalente entre casamento e união estável, sem abandonar a possibilidade de admitir a eficácia dos laços afetivos paralelos, sólidos, contínuos e duradouros, que se enquadram no conceito de família. Ademais, o matrimônio5, instituto com raízes católicas, foi enrijecido pela cultura brasileira e dogmatizado pelos exegetas do século passado, circunstância que obstrui, ainda mais, a harmonia interpretativa entre casamento e união estável.

4 "The family is the natural and fundamental group unit of society and is entitled to protection by society and the State". UN General Assembly. Universal Declararion of Human Rights. 217 (III) A. Paris, 1948. Disponível em: <https://www.ohchr.org/EN/UDHR/Documents/UDHR_Translations/eng.pdf> Acesso em 30 ago 2018.

5 Código de Direito Canônico, Cânone 1055 - \$1. "O pacto matrimonial, pelo qual o homem e a mulher constituem entre si o consórcio íntimo de toda a vida, ordenado por sua índole natural ao bem dos cônjuges e à procriação e educação da prole, entre os baptizados foi elevado por Cristo Nosso Senhor à dignidade de sacramento" (PAPA JOÃO PAULO II. Código de Direito Canônico. 4 ed. Lisboa, Portugal: Conferência Episcopal Portuguesa, 1983, p. 186). 
PESSOA COM DEFICIÊNCIA MENTAL OU INTELECTUAL: UM ESTUDO SOBRE CASAMENTO E UNIÃO ESTÁVEL NA PERSPECTIVA DA LEI BRASILEIRA DE INCLUSÃO

MARCELO PEREIRA dos SANTOS EDNA RAQUEL RODRIGUES SANTOS HOGEMANN

Contrariamente à concepção acima descrita, Xavier6 refuta a ideia de equiparação entre casamento e união estável por entender verdadeira afronta aos intentos do constituinte, salientando, que apesar de não pretender escalonar uma hierarquia entre arranjos familiares, a norma constitucional estaria canalizada para enumeração de “diversas espécies” de família “em igualdade de situações, no sentido de dar concretude aos princípios da dignidade humana e da isonomia. Outrossim, ressalta que, o objetivo da Constituição da República de 1988 foi assegurar a autonomia privada quanto à opção pela informalidade da vida em comum, possibilitando ao casal se afastar das amarras legais e definir a extensão dos efeitos experimentados durante a convivência.

Seja no casamento, na união estável ou qualquer outra configuração do formato familiar, é indispensável reconhecer o valor do afeto como instrumento mais expressivo da dignidade humana e semente para indução da felicidade entre pessoas, que compactuam com um projeto de vida. Dessa forma, permitir ao deficiente intelectual ou mental o exercício do seu direito para constituição de elos afetivos, outorgados pelo Estado e reconhecido pela sociedade, como instituição da família provida de garantias jurídicas atinentes aos efeitos pessoas, sociais e patrimoniais, revela a maior expressão do significado da Lei Brasileira de Inclusão, da Convenção sobre os Direitos das Pessoas com Deficiência e da Constituição, atribuído ao indivíduo como cidadão e ser ocupante do epicentro da ordem jurídica.

A pessoa com deficiência mental7 ou intelectual8 não pode ser impedida de exercer sua cidadania e liberdades enquanto ser humano, munido de parcela do poder, que conduz os rumos

6 XAVIER, Fernanda Dias. União Estável e Casamento: a impossibilidade de equiparação à luz dos princípios da igualdade e da liberdade. Dados eletrônicos. Brasília, TJDFT, 2015, p. 14. (Disponível em: <http://www.tjdft.jus.br/institucional/escola-de-administracao-judiciaria/plano-instrucional/e-books/ebooks-pdf/uniao-estavel-e-casamento>. Acesso em: 30 abr. 2017).

7 A Associação Americana de Deficiência Mental define deficiência mental como sendo o estado de redução notável do funcionamento intelectual significativamente inferior à média, associado a limitações pelo menos em dois aspectos do funcionamento adaptativo: comunicação e cuidados pessoais, competências domésticas, habilidades sociais, utilização dos recursos comunitários, autonomia, saúde e segurança, adaptações escolares, lazer e trabalho - durante o desenvolvimento infantil, até que atinja 18 anos de idade (AMERICAN PSYCHIATRY ASSOCIATION. Diagnostic and Statistical Manual of Mental Disorders - DSM-5. 5th.ed. Washington: American Psychiatric Association, 2013).

8 A Lei $n^{\circ} 13.146 / 2015$ utilizou a expressão deficiência mental ou intelectual ao alterar o texto legislativo do art. 1.550 , § $2^{\circ}$ e do art. 1.769 , I. No que tange a deficiência intelectual há atualmente maior consenso na adoção desta terminologia: "Intellectual disability is characterized by significant limitations both in intellectual functioning and in adaptive behavior as expressed in conceptual, social, and practical adaptive skills. This disability originates before age 18" (SCHALOCK, Robert L.; LUCKASSON, Ruth A.; SHOGREN, Karrie A. The Renaming of Mental Retardation: Understanding the Change to the Term Intellectual Disability, Intellectual and Developmental Disabilities, v. 45, n. 2, abr. 2007, p. 118). É 
PESSOA COM DEFICIÊNCIA MENTAL OU INTELECTUAL: UM ESTUDO SOBRE CASAMENTO E UNIÃO ESTÁVEL NA PERSPECTIVA DA LEI BRASILEIRA DE INCLUSÃO

MARCELO PEREIRA dos SANTOS EdNA RAQUEL RODRIGUES SANTOS HOGEMANN

do Estado democrático de direito em prol do bem comum, tal como responsável pelas escolhas, que dão sentido a sua existência. Assim sendo, tanto o casamento quanto a união estável são capazes de promover um ambiente saudável, seguro e digno para todos aqueles que foram rejeitados pela ordem jurídica brasileira e subjugados às mazelas da interdição, a qual poderia ser equiparada à morte civil9.

Consagrando essas diretrizes, o artigo $6^{\circ}$, da Lei Brasileira de Inclusão, dispôs que "a deficiência não afeta a plena capacidade civil das pessoas, inclusive para casar-se e constituir união estável”10, fixando um novo paradigma no âmbito do Direito de Família, o qual exonera-se de um modelo médico para erguer liberdades e garantias, nunca antes experimentadas pelas pessoas incapacitadas, tomando como referencial aspectos de natureza social11. Esse foi o direcionamento da Convenção de Direitos da Pessoa com Deficiência12 (Convention on the

conceito que inclui aquelas pessoas que possuem dificuldades na sua funcionalidade intelectual, considerado o ambiente sociocultural em que está inserido como, por exemplo, as pessoas com síndrome de Down. Já o termo deficiência mental não é utilizado de maneira pacífica pela comunidade internacional, podendo ser substituído por outros como "deficiência psicossocial"; diz respeito às pessoas que são diagnosticadas com e/ou vivenciam problemas de saúde mental, tais como transtorno bipolar, autismo e esquizofrenia (COUNCIL OF EUROPE PUBLISHING. Commissioner for human rights. Who gets to decide? Right to legal capacity for persons with intellectual or psychosocial disabilities. France; Council of Europe Publishing, 2012, p. 9).

9 Article 12 of the Convention on the Rights of Persons with Disabilities requires States parties to recognize persons with disabilities as individuals before the law, possessing legal capacity, including capacity to act, on an equal basis with others. [...] The centrality of this article in the structure of the Convention and its instrumental value in the achievement of numerous other rights should be highlighted" (UNITED NATIONS, General Assembly Human Rights Council (2009). Thematic Study by the Office of the United Nations High Commissioner for Human Rights on enhancing awareness and understanding of the Convention on the Rights of Persons with Disabilities, A/HRC/10/48, 26 January 2009, paragraph 43).

10 BRASIL. Lei 13.146 de 6, de julho de 2015. "Institui a Lei Brasileira de Inclusão da Pessoa com Deficiência (Estatuto da Pessoa com Deficiência)", publicada no DOU de 7.7.2015.

11 Para Pérez Bueno e Lorenzo García, ao contrário da perspectiva sustentada pelo modelo médico, desde os anos sessenta e setenta do século passado, começa a abrir caminho para um novo conceito, que altera a visão tradicional da incapacidade, superando o foco do individual para o social. Dessa forma, os componentes médicos são fortemente atenuados diante de uma concepção de incapacidade atrelada à ausência de interação social e aos fatores ambientais. Portanto, é necessário desfazer os obstáculos, que inviabilizam o agir humano das pessoas com deficiência mental ou intelectual e ampliar a integração das diversidades, através do gerenciamento das diferenças (PÉREZ BUENO, Luis Cayo; LORENZO GARCÍA, Rafael. Los difusos limites de la discapacidad en el futuro. Hacia un nuevo estatuto de la discapacidad. In: Tratado sobre discapacidad. LOURENZO, Rafael de. y PÉREZ BUENO, Luiz Cayo (Diretores). Navarra: Editorial Aranzadi, SA, 2007, p. 1553).

12 A Convenção de Direitos da Pessoa com Deficiência superou o modelo médico para definição da capacidade civil, assegurando aos maiores de 18 anos, ainda que diagnosticados com alguma espécie de deficiência mental ou intelectual, o exercício da autonomia privada para garantia da dignidade humana. Nessa perspectiva, os direitos de caráteres existencial e patrimonial das pessoas com deficiência ganharam novo significado na ordem jurídica mundial. Nos termos da própria convenção, a deficiência é um conceito evolutivo que varia de acordo com a remoção de barreiras ambientais, as quais dificultam a plena e efetiva participação da pessoa na sociedade, de forma equitativa e sem discriminação (FINA, 
PESSOA COM DEFICIÊNCIA MENTAL OU INTELECTUAL: UM ESTUDO SOBRE CASAMENTO E UNIÃO ESTÁVEL NA PERSPECTIVA DA LEI BRASILEIRA DE INCLUSÃO

MARCELO PEREIRA dos SANTOS EDNA RAQUEL ROdRIGUES SANTOS HOGEMANN

Rights of Persons with Disabilities - CRPD) que estabeleceu como principal vetor para 0 tratamento jurídico das pessoas com deficiência o princípio da não discriminação13.

Em prestígio a tais descrições, o Código Civil de 2002 foi alterado por força da Lei $\mathrm{n}^{\circ}$ 13.146/2015 para readequação das regras relativas à capacidade civil, passando a admitir o casamento de pessoas com deficiência mental ou intelectual. Ainda sim, dispôs que o consentimento para o matrimônio poderia ser declarado expressamente, por manifesta vontade direta, ou traduzida pelos responsáveis ou curadores (artigo 1.550, §2 ${ }^{\circ}, \mathrm{CC} / 02$ ). Sobre este último ponto é inaugurada a discussão sobre a extensão da norma quanto à anuência para a formação da família pela aliança de vida, proclamada por terceiro (responsável, curador ou apoiador).

Apesar do CC/02 não ter sido alterado na parte que trata da união estável, a regra acima discriminada requer interpretação extensiva aos pactos de convivências, ampliando a liberdade de escolha das pessoas com deficiência, com a finalidade de viabilizar a adequação do modelo de família que melhor atender seus interesses.

\section{VONTADE DECLARADA E VONTADE TRADUZIDA}

A capacidade de agir da pessoa com deficiência, por mais que seja resguardada na sua inteireza pela ordem jurídica, requer tratamento diferenciado em determinados casos, em especial, quando está impossibilitada de exprimir sua vontade ou não tem discernimento para governar a si mesmo. Significa dizer que se encontra em um estado de saúde mental que obsta a compreensão econômica, política, moral, técnica, dentre outras especificidades, que torna sua decisão um potencial perigo para seus próprios interesses, demandando cuidado de terceiros habilitados a exercer direitos e deveres, dirigidos às práticas beneficentes em prol da sua dignidade14.

O Código Civil de 2002 estabeleceu um critério seletivo para afastar a capacidade das pessoas com deficiência mental ou intelectual, fundado em um critério patrimonialista, levando

Valentina Della. The United Nations Convention on the Rights of Persons with Disabilities: a commentary. Rome, Italy: Springer International Publishing, 2017, p. 97).

13 EUROPEAN UNION AGENCY FOR FUNDAMENTAL RIGHTS. Legal Capacity of Persons with Intellectual Disabilities and Persons with Mental Health Problems. Luxembourg: Publications Office of the European Union, 2013, p. 14

14 STANZIONE, Pasquale. Capacità (diritto privato). In: AUTORINO, Gabriela; STANZIONE, Pasquale. Diritto civile e situazioni esistenziali. Torino: Giappichelli, 1997, p. 56. 
PESSOA COM DEFICIÊNCIA MENTAL OU INTELECTUAL: UM ESTUDO SOBRE CASAMENTO E UNIÃO ESTÁVEL NA PERSPECTIVA DA LEI BRASILEIRA DE INCLUSÃO

MARCELO PEREIRA dos SANTOS EdNA RAQUEL RODRIGUES SANTOS HOGEMANN

em consideração a inexpressividade da autonomia dos atos da vida civil por aqueles considerados loucos ou acometidos por anomalias psíquicas15. Esta orientação foi superada pela Lei $\mathrm{n}^{\circ}$ 13.146/2015 (Lei Brasileira de Inclusão), que institui o critério cronológico como único parâmetro para incapacidade absoluta, ficando consignada para tanto a idade de 16 anos incompletos.

Não menos importante, a Lei Brasileira de Inclusão apartou-se do regime da interdição para afiliar-se à curatela e à tomada de decisão apoiada, diante da excepcionalidade da capacidade relativa, estatuindo uma simetria entre o Código Civil de 2002, a Convenção sobre Direitos das Pessoas com Deficiência (CDPD) e o Decreto Legislativo $n^{\circ} 186$, que incorporou a norma internacional à ordem jurídica brasileira, concedendo a ela status de emenda constitucional, na forma do $5^{\circ}, \S 3$, da Constituição da República16. Entretanto, o Novo Código de Processo Civil resgatou o instituto da interdição por meio dos artigos 747 a 758 , contrariando princípios e preceitos consagrados através do poder constituinte derivado, com aderência às cláusulas pétreas descritas no artigo 60, \$4 $4^{\circ}$ inciso IV da CRFB/1988. À vista disto, o CPC/2015 entrou em vigor com uma dose de inconstitucionalidade, sendo compreendido todo tratamento da interdição como regra não recepcionada.

A deficiência por si só não impede o exercício da autonomia privada, visto que, em determinados casos, o distúrbio funcional, mental ou intelectual, não afeta o discernimento no momento das escolhas e da autodeterminação da pessoa inserida no contexto das relações jurídicas, ainda que necessite de alguma espécie de amparo. Diante disso, o tráfego de informações e a acessibilidade não podem ser cercados de obstáculos, sob pena de inviabilizar a emancipação daqueles que dependem de meios adequados para atingir os seus fins17.

Vale lembrar que, a conjuntura mundial posterior à Segunda Grande Guerra impôs diretrizes para edificar um sistema de blindagem sobre os direitos humanos e fundar uma rede de proteção capaz de enfrentar os influxos dos governos totalitários, a fim de minimizar e neutralizar os princípios do fascismo e do nazismo. Isto posto, a Declaração Universal da ONU de

15 RODOTÀ, Stefano. La vita e le regole: tra diritto e non diritto. Milão: Feltrinelli, 2006, p. 26 16 MACHADO, Diego Carvalho. Capacidade de Agir e Direitos da Personalidade no Ordenamento Jurídico Brasileiro: o caso do direito à privacidade. Revista Brasileira de Direito Civil. Vol. 8, abr./2016, p. 55.

17 Durante o Estado Liberal, o Direito não levou em conta as singularidades de cada sujeito, único e individualizado na sua existência, sustentando uma igualdade formal e abstrata sob do discurso retórico do combate às desigualdades (MORAES, Maria Celina Bodin de; CASTRO, Thamis Dalsenter Viveiros de. A autonomia existencial nos atos de disposição do próprio corpo. Revista Pensar, Universidade de Fortaleza, vol. 19, n. 3, set./dez. 2014, p. 786). 
PESSOA COM DEFICIÊNCIA MENTAL OU INTELECTUAL: UM ESTUDO SOBRE CASAMENTO E UNIÃO ESTÁVEL NA PERSPECTIVA DA LEI BRASILEIRA DE INCLUSÃO

MARCELO PEREIRA dos SANTOS EdNA RAQUEL RODRIGUES SANTOS HOGEMANN

1948 exprimiu o desejo de emancipação e solidariedade, descrevendo, que "os seres humanos nascem livres e iguais em dignidade e direitos"18

O livre desenvolvimento da personalidade do indivíduo é algo ínsito à sua natureza, circunstância que não pode ser obstada pelo Estado, através de suas normas, uma vez que se faz necessário preservar o espaço destinado ao exercício da privacidade e da intimidade, a fim de garantir a consolidação de plano de vida. É na intimidade que reside o sentimento, o desejo e a vontade de definir o caminho a ser seguido para alcançar a dignidade. Por outro lado, a privacidade, por si só, não permite alguém identificar-se na sua integralidade psicofísica, dependendo da conexão com aquele último elemento para que seja reduzida a incompletude das pessoas que buscam se completar, apesar da certeza de serem, para toda vida, incompletas19.

A convivência com o outro é algo que preenche o vazio do ser e, portanto, a medida que estabelece ciclos de relacionamentos vai constituído sua autonomia e identidade. Para tanto, a Constituição da República de 1988 ergueu os pilares da autonomia privada existencial, assegurando as liberdades individuais no sentido de assegurar a manifestação da cidadania e a autodeterminação, sem atingir valores consagrados no âmbito da ética regulada e da moral juridicizada.

É certo que, a definição do tracejo da vida decorre da vontade manifestada pela pessoa, dotada de liberdade e autonomia para fazer suas escolhas, porém há circunstâncias na órbita da saúde mental, que tornam impraticável sua exteriorização. Todavia, é plenamente possível, numa sociedade globalizada e marcada pelos riscos da evolução científica e tecnológica, criar mecanismos que se adequem a peculiaridade de cada indivíduo para facilitar a expressão do querer e do não querer, ainda que de maneira traduzida.

Nem sempre a vontade é manifestamente verbal, podendo resultar de um gesto, um olhar ou da fisionomia que, uma vez interpretada, terá significado e sentido para aquele que está temporária ou permanentemente limitado por seu estado de saúde mental ou intelectual, bem como para todos aqueles que o cercam, a partir do momento em que o universo começa a compreender o caminho que quer seguir em busca da felicidade.

18 PIOVESAN, Flávia. Introdução ao sistema interamericano de proteção dos direitos humanos: a convenção americana de direito humanos. In: GOMES, Luiz Flávio; PIOVESÁN, Flávia (Coord.). O sistema interamericano de proteção dos direitos humanos e o direito brasileiro. São Paulo: Editora Revista dos Tribunais, 2000.

19 "A dignidade humana não depende das circunstâncias externas, a partir de papéis sociais ocupados pelos indivíduos, mas é um valor inerente ao ser humano como tal” (MENGONI, Luigi. Diritto e valori. Bologna: II Mulino, 1985, p. 123). 
PESSOA COM DEFICIÊNCIA MENTAL OU INTELECTUAL: UM ESTUDO SOBRE CASAMENTO E UNIÃO ESTÁVEL NA PERSPECTIVA DA LEI BRASILEIRA DE INCLUSÃO

MARCELO PEREIRA dos SANTOS EdNA RAQUEL ROdRIGUES SANTOS HOGEMANN

Entretanto, o Estado- englobando a comunidade politicamente ativa - optou por afastar as pessoas com deficiência mental ou intelectual das relações sociais, jurídicas e econômicas, desagravando o ônus de ter que fornecer meios necessários e adequados para desobstruir os canais de participação plena e efetiva na sociedade em igualdade de condições. Isso reflete o pensamento do legislador brasileiro, que não empregou esforços para adaptação do mundo das coisas, almejando a igualdade de oportunidades, pois se restringiu ao desejo de consertar as pessoas (modelo médico). Não diferente disso, o mercado seguiu na mesma direção, disseminando barreiras atitudinais, materializadas diariamente, através de condutas fundada em preconceitos e estereótipos que se propagaram ao longo da história, intensificando atos de discriminação, próprios das violências sistêmica e estrutural20. Por outro lado, o Decreto Legislativo $\mathrm{n}^{\circ}$ 186, de 9 de julho de 2008, definiu um novo arcabouço normativo, propondo o ajuste da sociedade em torno das diferenças inerentes à deficiência, com intuito de valorizar a autonomia individual, a liberdade de fazer escolhas e a independência das pessoas 21.

A regulamentação da matéria foi consagrada nas disposições da Lei Brasileira de Inclusão ( $n^{\circ} 13.146$ de 6 de julho de 2015), destacando em seu artigo $4^{\circ}$, que toda pessoa com deficiência tem direito à igualdade de oportunidades com as demais pessoas e não sofrerá nenhuma espécie de discriminação. Ademais, os efeitos dessa norma atingiram todas as relações jurídicas reguladas pelo Código Civil brasileiro de 2002 e, em especial, as regras inerentes ao casamento válido e a união estável.

Levando em consideração o princípio da dignidade humana, a pessoa com deficiência mental ou intelectual, ainda que não exteriorize sua vontade diretamente, uma vez atingida a idade núbio, poderá contrair matrimônio por intermédio do seu responsável ou curador, o qual servirá de canal para transmitir a escolha. Portanto, não há dúvida que existe a presença do elemento vontade, porém a forma pela qual é revelada consiste na tradução dos sentidos ou expressões compreendidas por aqueles que interagem diariamente com seus curatelados, pais, filhos, sobrinhos, etc., gozando de uma percepção mais aguçada sobre as decisões que transformam o ambiente ao redor da pessoa.

Nessa perspectiva, é inquestionável a constitucionalidade do artigo $1.550, \S 2^{\circ}$, da CRFB/1988, porque expande a autonomia privada da pessoa com deficiência, ainda que não

20 SCHULZE, Marianne. Tomada de decisões: somente para quem está no poder? Revista Deficiência Intelectual - DI, ano 5, n. 8, jan./jun. 2015, p. 5.

21 ORGANIZAÇÃ̃O DAS NAÇÕES UNIDAS. Convenção sobre os Direitos das Pessoas com Deficiência (CDPD). 2009. 
PESSOA COM DEFICIÊNCIA MENTAL OU INTELECTUAL: UM ESTUDO SOBRE CASAMENTO E UNIÃO ESTÁVEL NA PERSPECTIVA DA LEI BRASILEIRA DE INCLUSÃO

MARCELO PEREIRA dos SANTOS EdNA RAQUEL RODRIGUES SANTOS HOGEMANN

possa exteriorizar vontade, com intuito de proporcionar o exercício da liberdade de escolha em prestígio ao princípio da igualdade e da dignidade humana. Para tanto, os curadores e responsáveis, aos quais incumbe a tarefa de traduzir as intenções do relativamente capaz, devem agir com amparo no princípio da beneficência e não-maleficência22, ou seja, a leitura traduzida das escolhas não pode se afastar do "dever prima facie"23, pivô de contenção das arbitrariedades, tomando como referencial os ensinamentos de Ross: “o reconhecimento deste direito de não-maleficência é o primeiro passo no caminho para o reconhecimento do direito de beneficência"24.

\section{EXISTÊNCIA, VALIDADE E EFICÁCIA DO CASAMENTO DA PESSOA COM DEFICIÊNCIA MENTAL OU INTELECTUAL NA FORMA DA LEI BRASILEIRA DE INCLUSÃO}

Sob o ângulo do Direito de Família contemporâneo, delineado pelas transformações da sociedade pós-moderna, o casamento e a união estável têm o status de negócio jurídico, razão pela qual é exigida a presença dos elementos de existência, validade e eficácia para que tais institutos sejam reconhecidos na ordem jurídica. Outrossim, de acordo com os paradigmas hodiernos, a autonomia privada no âmbito das relações familiares não pode sofrer intervenções de quaisquer pessoas de direito público ou privado, exceto se houver ameaça ou lesão à direitos que atinjam a esfera da dignidade humana e coloquem em xeque as liberdades individuais.

o Código Civil brasileiro de 2002 dispõe no artigo 107, que a vontade declarada consiste em mais um elemento de existência do negócio jurídico, além daqueles descritos no artigo 104 do referido diploma legal. Por conseguinte, tais requisitos, quando ausentes no casamento e na união estável, configuram negócio jurídico inexistente. Vale registrar que, o princípio do

22 Segundo Frankena "o Princípio da Beneficência não nos diz como distribuir o bem e o mal. Só nos manda promover o primeiro e evitar o segundo. Quando se manifestam exigências conflitantes, o mais que ele pode fazer é aconselhar-nos a conseguir a maior porção possível de bem em relação ao mal..." (FRANKENA, Willian K. Ética. 2 ed., tradução de Leônidas Hegenberg e Octanny da Mota, Rio de Janeiro: Zahar, 1975, p. 61-73).

23 "The recognition of this duty of non-maleficence is the first step on the way to the recognition of the duty of beneficence; and that accounts for the prominence of the commands 'thou shalt not kill', 'thou shah not commit adultery', 'thou shalt not steal', 'thou shalt not bear false witness', in so early a code as the Decalogue. But even when we have come to recognize the duty of beneficence, it appears to me that the duty of non-maleficence is recognized as a distinct one, and as prima facie more binding. We should not in general consider it justifiable to kill one person in order to keep another alive, or to steal from one in order to give alms to another" (ROSS, W. D. The right and the Good. Oxford: Clarendon, 1930, p. 22).

24 ROSS, W. D. The right and the Good. Oxford: Clarendon, 1930, p. 21-22. 
PESSOA COM DEFICIÊNCIA MENTAL OU INTELECTUAL: UM ESTUDO SOBRE CASAMENTO E UNIÃO ESTÁVEL NA PERSPECTIVA DA LEI BRASILEIRA DE INCLUSÃO

MARCELO PEREIRA dos SANTOS EDNA RAQUEL RODRIGUES SANTOS HOGEMANN

consensualismo, almeja o respeito à palavra, ao real conteúdo da escolha, informado pela autonomia privada, “cujos efeitos se fazem sentir em significativa extensão na regulamentação das relações (...)"25. Todavia, há de salientar que, a intenção da pessoa pode ser exteriorizada por descrição textual, manifestações gestuais, silêncio circunstanciado, comportamento tácito e, ainda sim, por meio de tradução realizada por curado ou responsável. Essa última hipótese se adequa aos propósitos da Lei Brasileira de Inclusão (LBI) e permite o reconhecimento da vontade expressa pela pessoa com deficiência mental e intelectual, já que esta circunstância não afeta a capacidade civil para casar e constituir união estável.

0 artigo $1.550, \S 2^{\circ}$, do Código Civil, regra introduzida pela LBI, inovou a ordem jurídica brasileira no âmbito da validade do casamento, pois afastou a nulidade do matrimonio firmado por "enfermo mental, sem o necessário discernimento para os atos da vida civil"26 (texto anterior, previsto no artigo 1548, inciso I, CC/02). Isto posto, mesmo diante da vontade transmitida pelo intérprete da pessoa com deficiência, não mais há que se questionar a legalidade da união matrimonial de jovens e adultos com síndrome de Down, em situação de déficit intelectual ou afetados por transtornos de qualquer natureza.

Não se admite um juízo preliminar, fundando puramente na presunção de ausência de discernimento, sendo indispensável submeter a pessoa à perícia médica para apurar seu grau de entendimento e compreensão dos atos praticados. Dessa forma, os possíveis questionamentos em torno da incidência do artigo 217-A, \$1, do Código Penal (estupro de vulnerável) nas hipóteses de casamento ou união estável envolvendo pessoas com deficiência devem ser rechaçados num primeiro momento, pois, do contrário, a LBI poderá perder sua eficácia social, afetando o direito de constituir uma comunhão de vida, em busca da felicidade plena e solidificação da dignidade humana27. Portanto, a prevalência dos princípios indubio pro capacitas e da intervenção mínima

25 TEPEDINO, Gustavo; BARBOSA, Heloisa Helena; MORAES, Maria Celina Bodin. Código Civil Interpretado, conforme a Constituição da República, Volume 1: Parte Geral e Obrigações. $2^{\mathrm{a}}$ ed., rev. e atual. $1^{\mathrm{a}}$ Tiragem, Rio de Janeiro: Renovar, 2011, p. 222.

26 BRASIL. Lei 13.146 de 6, de julho de 2015. Institui a Lei Brasileira de Inclusão da Pessoa com Deficiência (Estatuto da Pessoa com Deficiência). In: Diário Oficial da República Federativa do Brasil, Brasília, DF, 07 jul. 2015. Disponível em: <http://www.planalto.gov.br/ccivil_03/_ato20152018/2015/lei/l13146.htm> Acesso em 09 set. 2018.

27 Ver Apelação Crime No 70054819487 (Sexta Câmara Criminal, Tribunal de Justiça do RS, Relator: Ícaro Carvalho de Bem Osório, Julgado em 19/12/2013): Ementa: “APELAÇÃO CRIMINAL. CRIME CONTRA A DIGNIDADE SEXUAL. VÍTIMA COM DEFICIÊNCIA MENTAL. DÚVIDA QUANTO A AUSENCIA DE DISCERNIMENTO PARA A PRÁTICA DO ATO SEXUAL. SENTENÇA ABSOLUTÓRIA MANTIDA. Para a configuração do tipo penal previsto no art. 217-A, § $1^{\circ}$ do Código Penal, é necessário que, além da enfermidade ou deficiência mental, esteja comprovado, modo idôneo, que a vítima não possuía o necessário discernimento para a prática do ato sexual. Caso em que não foi realizado um laudo 
PESSOA COM DEFICIÊNCIA MENTAL OU INTELECTUAL: UM ESTUDO SOBRE CASAMENTO E UNIÃO ESTÁVEL NA PERSPECTIVA DA LEI BRASILEIRA DE INCLUSÃO

MARCELO PEREIRA dos SANTOS EdNA RAQUEL RODRIGUES SANTOS HOGEMANN

são de fundamental importância para garantia da autonomia privada, da liberdade das decisões e da escolha das preferências28.

De acordo com o artigo 1513, do Código Civil brasileiro, “é defeso a qualquer pessoa, de direito público ou privado, interferir na comunhão de vida instituída pela família"29, razão pela qual não cabe ao Estado inviabilizar o casamento de pessoas com deficiência mental ou intelectual, até porque, na vida é possível ver de tudo, inclusive, o amor incondicionado pelo outro, sem que isso venha atingir o interesse público. A intervenção mínima nas relações de família é pressuposto para a dignidade dos membros inseridos nos núcleos interligados pelo afeto. Nessa perspectiva, afirma Pereira que "sob nova roupagem e assumindo novo papel, a família contemporânea não admite mais a ingerência do Estado, sobretudo no que se refere à intimidade de seus membros" 30, circunstância que revela "um notório processo de privatização das relações, com propagação da interferência mínima do Estado no âmbito das relações privada"31.

Para efeito do casamento civil, não se pode deixar de lado, a regra prevista no artigo 1514, CC/2002, que estabelece como condição para sua eficácia, a manifestação de vontade pelo desejo irrestrito em firmar o vínculo conjugal, bem como a declaração do juiz em torno da efetivação do matrimônio. Aqui, merece reforçar o entendimento de que a escolha por se dar por intermédio do curador (tradução), procuração ou tomada de decisão apoiada, não exigindo forma especial para que o ato jurídico seja válido e eficaz32.

Tratando ainda do plano de validade do casamento, merece destaque o fato da LBI ter revogado inciso I, do artigo 1.548, do Código Civil de 2002, restando apenas uma hipótese de

\footnotetext{
psiquiátrico e os pareceres firmados por profissionais da área da Psicologia não atestaram, com precisão e de forma objetiva, se vítima apresentava ou não discernimento suficiente acerca do fato ocorrido. A prova oral produzida no contraditório judicial tampouco permite a conclusão e a formação de um juízo de certeza acerca da ausência ou não de discernimento da ofendida, adolescente com 17 anos de idade, para emitir consentimento válido para a prática de relações sexuais. Dúvida que milita em favor do denunciado. Absolvição mantida. APELO MINISTERIAL DESPROOVIDO. UNÂNIME".

28 TESÓN, Inmaculada Vivas Tesón. Más allá capacidade de entender y querer... Um análisis de la figura italiana de la administración de apoyo y una de apoyo y una propuesta de reforma del sistema tuitivo español. Observatório Estatal de la Discapacidad. Olivenza: FUTUEX, 2012, p. 30.

29 BRASIL. Lei 13.146 de 6, de julho de 2015. "Institui a Lei Brasileira de Inclusão da Pessoa com Deficiência (Estatuto da Pessoa com Deficiência)", publicada no DOU de 7.7.2015.

30 PEREIRA, Rodrigo da Cunha. Princípios fundamentais norteadores do direito de família. Belo Horizonte: Del Rey, 2006, p. 156-157.

31 PEREIRA, Rodrigo da Cunha. Princípios fundamentais norteadores do direito de família. Belo Horizonte: Del Rey, 2006, p. 156-157.

32 Ver Código Civil Brasileiro, Art. 107: “A validade da declaração de vontade não dependerá de forma especial, senão quando a lei expressamente a exigir".
} 
PESSOA COM DEFICIÊNCIA MENTAL OU INTELECTUAL: UM ESTUDO SOBRE CASAMENTO E UNIÃO ESTÁVEL NA PERSPECTIVA DA LEI BRASILEIRA DE INCLUSÃO

MARCELO PEREIRA dos SANTOS EDNA RAQUEL RODRIGUES SANTOS HOGEMANN

nulidade no matrimônio que consiste na ocorrência de impedimento para a constituição do vínculo conjugal33, uma vez oposto durante o procedimento de habilitação (até a data da celebração) ou conhecido por sentença judicial de natureza declaratória, após propositura de ação por impulso do Ministério Público ou de qualquer pessoa capaz. Dessa forma, não mais subsiste razão para inviabilizar a formação da família matrimonial por vontade das pessoas com deficiência mental ou intelectual. Ademais, a falta de discernimento, seja transitória ou permanente, pode ser apontada como fundamento para anulabilidade da união civil, desde que seja manejada ação anulatória no prazo de 180 dias, a contar da data da celebração da cerimônia, pois do contrário, a núpcia será convalidada pelo decurso do tempo. Para tanto, exige-se prova pericial pré-constituída, demonstrando que a pessoa era incapaz de consentir ou manifestar, de modo inequívoco, o consentimento na ocasião da celebração, uma vez que, passado esse momento, os laços matrimoniais restariam consolidados, somente sendo possível desconstituir o vínculo conjugal através do divórcio. Não é demais lembrar que, o inciso IV, do artigo 1.557, do CC/02 foi revogado pela Lei n. 13.146/2015, rechaçando do ordenamento jurídico a anulação por erro essencial sobre a pessoa do outro cônjuge nos casos de doença mental preexistente ao casamento.

Em busca de ampla inserção das pessoas com deficiência mental e intelectual na órbita jurídica, que abriga as famílias, a Lei Brasileira de Inclusão trouxe a redefinição dos paradigmas atinentes ao casamento civil e da união estável, tal como fundou vetores da nova modernidade, aperfeiçoando os pressupostos de existência, validade e eficácia em proveito das múltiplas facetas dos seres humanos, de modo a salvaguardar a mais profunda camada da autonomia privada e da personalidade.

\section{VONTADE TRADUZIDA E PACTO ANTINUPCIAL}

Um dos efeitos decorrentes do matrimônio atinge a seara patrimonial, aspectos que arrepia parte da doutrina clássica porque, muitas vezes, as alianças de vida impactam na divisão de bens e interesses econômicos, circunstância que se revela como fato difusor de desavenças e

33 Art. 1.521. "Não podem casar: I - os ascendentes com os descendentes, seja o parentesco natural ou civil; II - os afins em linha reta; III - o adotante com quem foi cônjuge do adotado e o adotado com quem o foi do adotante; IV - os irmãos, unilaterais ou bilaterais, e demais colaterais, até o terceiro grau inclusive; V - o adotado com o filho do adotante; VI - as pessoas casadas; VII - o cônjuge sobrevivente com o condenado por homicídio ou tentativa de homicídio contra o seu consorte". 
PESSOA COM DEFICIÊNCIA MENTAL OU INTELECTUAL: UM ESTUDO SOBRE CASAMENTO E UNIÃO ESTÁVEL NA PERSPECTIVA DA LEI BRASILEIRA DE INCLUSÃO

MARCELO PEREIRA dos SANTOS EdNA RAQUEL ROdRIGUES SANTOS HOGEMANN

ruptura dos laços de afeto. Entretanto, quando a questão abrange pessoas com deficiência mental e intelectual, a matéria ganha maior densidade, pois compreende-se que, a debilidade psíquica conduz à vulnerabilidade, dando margem para a aproximação de especuladores e oportunistas. Vale salientar que, esse julgamento antecipado consiste em mera dedução, não podendo servir de justificativa para impedir a eficácia jurídica do casamento e da união estável firmado mediante exercício da curatela, em benefício dos interesses do curatelado, ou por intermédio de decisão apoiada, na perspectiva de preservar o direito à convivência familiar e comunitária.

Sob a lógica civil-constitucional do século XXI, importa para o Direito a mínima proporção do patrimônio, desde que seja suficiente para garantir a dignidade humana numa sociedade bem ordenada34, diante da concepção de Rawls35 abarcando os princípios de justiça acolhidos pelos sujeitos de uma comunidade democrática, na qual os cidadãos são dotados de liberdades e igualdades para evoluir de modo apropriado e constituir seus atributos morais, e consequentemente terem a oportunidade de ser "membros normais e plenamente cooperativos da sociedade".

Uma vez assegurada a autonomia e a liberdade de escolha pelo estatuto patrimonial do casamento, é de substancial relevância apontar para os desdobramentos da opção do regime de bens por expressão traduzida e declarada pelo curador ou responsável da pessoa com deficiência mental ou intelectual, quando do procedimento de habilitação junto ao Registro de Pessoas Naturais, não cabendo aqui, a percepção precipitada de que, o exclusivo interesse econômico do outro nubente ou condutas fraudulentas estarão sempre presentes no ato, circunstância que poderia se enquadrar no conceito de simulação e, por conseguinte, configurar negócio jurídico nulo. Se assim fosse, estaria suplantado o princípio da liberdade dos regimes de bens, uma vez que restarei sujeitar-se às regras da comunhão parcial, nos termos do artigo 1.640, do Código Civil. Pior seria sugerir a incidência do regime legal da separação compulsória, o que equivaleria à interpretação ampliativa para restrição de direitos, difundindo verdadeira afronta à dignidade humana.

34 Aproximando as descrições consignadas à Teoria da Justiça de Rawls, destaca-se que numa sociedade bem ordenada pelos princípios de justiça como equidade "os cidadãos são iguais no mais alto nível e nos aspectos fundamentais (RAWLS. John. Justice as Fairness: a restatement. Cambridge: Harvard University Press, 2001, p. 132). Ademais, segundo Weber, a sociedade bem ordenada é reflexo dos princípios de justiça que são reconhecidos e compartilhados por todos os seus membros (WEBER, Thadeu. A ideia de um mínimo existencial de J. Rawls. Kriterion, Revista de Filosofia, Belo Horizonte, no 127, Jun./2013, p. 200).

35 RAWLS. John. Justice as Fairness: a restatement. Cambridge: Harvard University Press, 2001, p. 71. 
PESSOA COM DEFICIÊNCIA MENTAL OU INTELECTUAL: UM ESTUDO SOBRE CASAMENTO E UNIÃO ESTÁVEL NA PERSPECTIVA DA LEI BRASILEIRA DE INCLUSÃO

MARCELO PEREIRA dos SANTOS EdNA RAQUEL RODRIGUES SANTOS HOGEMANN

Evidentemente, tomando por base o princípio da eticidade e seus desdobramentos por meio da imperatividade da boa fé objetiva, os pactos antenupciais formulados por curadores, responsáveis ou tomados de decisão apoiada não estão dissociados do dirigismo contratual e da intervenção mínima do Estado sobre as famílias, sendo, plenamente, possível o controle do Judiciário com fundamento na inafastabilidade de jurisdição, uma vez provocado pelas partes interessadas. Significa dizer que, o abuso do direito e os atos atentatórios serão classificados como ilícitos e suscetíveis à responsabilidade civil e penal, podendo o causador do dano responder pelos danos morais e materiais, na medida da sua extensão, assim como as penas previstas nos artigos 89 e 91, da LBI, comprovada a prática dos crimes lá especificados.

Quando da lavratura da escritura pública para efetivação do pacto antenupcial, fica a cargo do tabelião a apuração da autêntica intenção dos nubentes quanto à escolha do regime de bens e os termos atinentes a comunicação do patrimônio, a fim de mitigar os riscos tocantes à apropriação indevida da riqueza do outro, de maneira ilícita. Tal atribuição não é novidade na ordem jurídica brasileira, haja vista as disposições dos artigos $6^{\circ}, 7^{\circ}$, parágrafo único, da Lei $n^{\circ}$ 8.935/94, não deixando de lado a repercussão decorrente de condutas culposas ou dolosas, que geram prejuízo, em conformidade com o artigo 22 do referido diploma legal.

Em razão da natureza de negócio jurídico, o pacto antenupcial acordado entre os noivos requer a presença dos elementos previstos no artigo 104, do CC/02, além da forma especial determinada no artigo 108. Não obstante estarem presentes circunstâncias que viciem a vontade, a invalidade do ajuste firmado entre os nubentes depende de decisão judicial ante a propositura de ação anulatória, dentro do prazos previstos nos artigos 178 (4 anos) e 179 (2 anos). Por outro lado, constatada a inobservância da forma (escritura pública) ou o intuito de simular a transação pactuada pela tradução exteriorizada pelo curador ou responsável da pessoa com deficiência mental ou intelectual, fica evidenciada a nulidade, que também demanda sentença do juiz, com caráter declaratório, independente de prazo.

Em quaisquer das hipóteses retratadas acima, passa a vigorar o regime da comunhão parcial, de modo subsidiário, prevalecendo as regras previstas entre os artigos 1.658 a 1.666, do CC/02. Portanto, a vontade traduzida não pode ser interpretada como um cheque em branco ou um formulário a ser preenchido ao arbítrio dos curadores ou responsáveis, mas sim externar o desejo mais próximo da vontade exposta pela pessoa com deficiência, sob o abrigo dos princípios da boa-fé objetiva e da função social dos contratos. 
Mais valioso do que preocupar-se com as consequências do matrimônio e a escolha do regime de bens, é garantir às pessoas com deficiência mental ou intelectual o direito de exercerem sua autonomia privada para constituírem suas famílias e se inserirem no convívio social entrelaçado pelas manifestações de afeto, oportunizado a felicidade e a solidificação da dignidade no seu plano mais intenso.

\section{CONCLUSÃO}

A Lei Brasileira de Inclusão é o marco normativo da capacidade civil constitucional que tem por finalidade reforçar a concepção de dignidade da pessoa humana, definindo um complexo de ações a serem postas em prática pelo poder estatal, assim como pela sociedade civil. Do mesmo modo, propõe a observância de regras que elevam as pessoas com deficiência ao status de cidadão, senhor da sua autonomia e dono das suas escolhas. Ainda assim, requer uma postura solidária para equilíbrio das relações jurídicas e amplitude do conceito de justiça.

No âmbito do Direito de Família, o teor da referida norma se espraia sobre os requisitos do casamento e da união estável, com propósito de garantir o convívio afetivo às pessoas etiquetadas como deficientes mentais ou intelectuais. Nesse sentido, homens e mulheres são libertados das correntes da interdição e das amarras do isolamento árido, escuro e sombrio, sendo possível preencher o coração de amor e alimentar a alma com o fogo da paixão.

Apesar da boa intenção do legislador brasileiro, de nada adiantará todo o esforço normatizado em torno do direito das pessoas com deficiência se não houver uma mudança interna em cada um dos indivíduos que compõe o corpo social, além da transformação cultural sobre o ser humano como um fim em si mesmo. Basta imaginar, que o mundo ideal não depende apenas da lei, mas requer atitudes que influenciem as circunstâncias para melhoria das condições de vida num universo cercado de ambivalências e múltiplas contingências.

A família contemporânea é compreendida como meio para efetivação plena da dignidade humana, estendendo-se aos mais diversos arranjos projetados pelos seus membros, não importando a origem, o gênero, a etnia, a religião, a orientação sexual e a idade, dentre outros aspectos ligados ao indivíduo. Em outras palavras, pode ser considerado um agrupamento de pessoas, unidas pelo propósito de manter a comunhão de vida, permeada pelo afeto que 
PESSOA COM DEFICIÊNCIA MENTAL OU INTELECTUAL: UM ESTUDO SOBRE CASAMENTO E UNIÃO ESTÁVEL NA PERSPECTIVA DA LEI BRASILEIRA DE INCLUSÃO

MARCELO PEREIRA dos SANTOS EdNA RAQUEL ROdRIGUES SANTOS HOGEMANN

pulsa no âmago do peito dos seus integrantes, guardando como principal ideal, a busca pela felicidade.

Se sua nascente reside no íntimo desejo de estabelecer laços de afetividade, deve sempre prevalecer a mínima intervenção do Estado e da sociedade sobre as relações familiares, admitindo-se exclusivamente, o emprego de mecanismo de interferência quando do risco de lesão aos direitos fundamentais e a própria dignidade. Isto posto, é completamente desconexa a ideia de impedir o casamento ou a união estável de pessoas com deficiência mental ou intelectual. Vale salientar que, ainda que estejam impossibilitadas de exprimir vontade de forma verbal, o matrimônio e o pacto de convivência podem ser firmados validamente por intermédio de curadores ou responsáveis, não restando dúvida, que todos são dotados de autonomia privada para fazerem suas escolhas, não obstante, seja de forma traduzida.

Tomando por base o princípio da precaução, é fundamental que os tabeliães e registradores façam as diligências necessárias para enviar prejuízo aos interesses da pessoa com deficiência, pois essa tarefa está inserida nas suas atribuições funcionais. Do contrário, evidenciado o descuido ou a conduta dolosa para prática de condutas ilícitas, serão eles passíveis de responsabilidade administrativa, civil e criminal, nos termos da Lei $n^{\circ}$ 8.935/94. Da mesma forma, os curadores e responsáveis, se agirem com intuito fraudulento poderão ser penalizados e sofrerem todos os desdobramentos sancionatórios previstos na ordem jurídica.

A declaração traduzida será conhecida para efeito de validade do negócio jurídico, inclusive no que tange ao pacto antinupcial, uma vez identificada a presença de todos os demais elementos do artigo 104, a ausência de impedimentos, previstos no artigo 1.521 e lavratura de escritura pública, nos termos do artigo 1653, ambos do Código Civil. Por outro lado, em se tratando de união estável, bastará a definição do contrato de convivência por documento particular, seguindo a lógica do artigo 1.725 do mesmo diploma legal.

Um dos pontos que continuará despertando curiosidade refere-se à escolha do cônjuge ou companheiro, diante da vontade traduzida pelo curador ou responsável, uma vez que não será fácil descobrir se o pretendente da pessoa com deficiência foi induzido ou aproximado por proposta do próprio nubente/convivente ou proveniente da articulação e dissimulação do tradutor, escondendo uma aspiração inautêntica de manter o vínculo afetivo em prol da felicidade do casal. Entretanto, não cabe à sociedade fazer um juízo antecipado de valor, tendo em conta, o fato da família enquadrar-se no plano da intimidade ou circunstância que exige a máxima preservação da autonomia privada.

Revista Eletrônica do Curso de Direito da UFSM www.ufsm.br/revistadireito v. 13, n. 3 / 2018 p.904-926 
Ainda que seja certa a incompletude do ser humano, é imprescindível propiciar meios que oportunize a pessoa satisfazer o desejo de caminhar na direção do preenchimento da felicidade e adquirir tudo aquilo que the faça sentir completo. Dessa forma, obstruir a autodeterminação de quaisquer cidadãos reflete o esfacelamento dos sonhos, bem como esgotamento do sentido da vida e descrença na convicção de que o indivíduo é um fim em si mesmo.

\section{REFERÊNCIAS}

AMERICAN PSYCHIATRY ASSOCIATION. Diagnostic and Statistical Manual of Mental Disorders DSM-5. 5th.ed. Washington: American Psychiatric Association, 2013.

BRASIL. Lei 13.146 de 6, de julho de 2015. Institui a Lei Brasileira de Inclusão da Pessoa com Deficiência (Estatuto da Pessoa com Deficiência). In: Diário Oficial da República Federativa do Brasil, Brasília, DF, 07 jul. 2015. Disponível em:

<http://www.planalto.gov.br/ccivil_03/_ato2015-2018/2015/lei/l13146.htm> Acesso em: 09 set. 2018.

COUNCIL OF EUROPE PUBLISHING. Commissioner for human rights. Who gets to decide? Right to legal capacity for persons with intellectual or psychosocial disabilities. France; Council of Europe Publishing, 2012

EUROPEAN UNION AGENCY FOR FUNDAMENTAL RIGHTS. Legal Capacity of Persons with Intellectual Disabilities and Persons with Mental Health Problems. Luxembourg: Publications Office of the European Union, 2013.

FRANKENA, Willian K. Ética. 2. ed., tradução de Leônidas Hegenberg e Octanny da Mota, Rio de Janeiro: Zahar, 1975.

FINA, Valentina Della. The United Nations Convention on the Rights of Persons with Disabilities: a commentary. Rome, Italy: Springer International Publishing, 2017.

KANT, I. A Metafísica dos Costumes. Trad. de Edson Bini. 1 ed. Bauru: Edipro, 2003.

MACHADO, Diego Carvalho. Capacidade de Agir e Direitos da Personalidade no Ordenamento Jurídico Brasileiro: o caso do direito à privacidade. Revista Brasileira de Direito Civil. Vol. 8, abr./2016, p. 47-80.

MENGONI, Luigi. Diritto e valori. Bologna: II Mulino, 1985.

MORAES, Maria Celina Bodin de; CASTRO, Thamis Dalsenter Viveiros de. A autonomia existencial nos atos de disposição do próprio corpo. Revista Pensar, Universidade de Fortaleza, vol. 19, n. 3, set./dez. 2014, p. 779-818. 


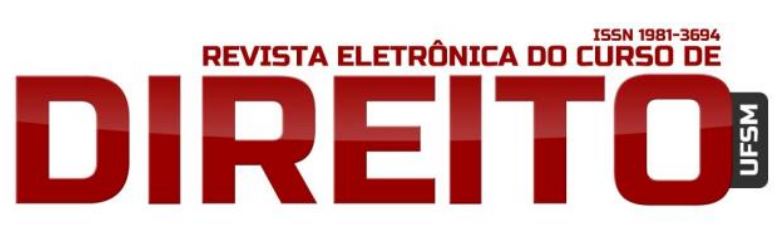

PESSOA COM DEFICIÊNCIA MENTAL OU INTELECTUAL: UM ESTUDO SOBRE CASAMENTO E UNIÃO ESTÁVEL NA PERSPECTIVA DA LEI BRASILEIRA DE INCLUSÃO

Marcelo Pereira dos Santos EdNa RaQuel Rodrigues SANTOS HOGEMANN

ORGANIZAÇÃO DAS NAÇÕES UNIDAS. Convenção sobre os Direitos das Pessoas com Deficiência (CDPD). 2009.

PAPA JOÃO PAULO II. Código de Direito Canônico. 4 ed. Lisboa, Portugal: Conferência Episcopal Portuguesa, 1983.

PEREIRA, Rodrigo da Cunha. Princípios fundamentais norteadores do direito de família. Belo Horizonte: Del Rey, 2006.

PÉREZ BUENO, Luis Cayo; LORENZO GARCÍA, Rafael. Los difusos limites de la discapacidad en el futuro. Hacia un nuevo estatuto de la discapacidad. In: Tratado sobre discapacidad. LOURENZO, Rafael de. y PÉREZ BUENO, Luiz Cayo (Diretores). Navarra: Editorial Aranzadi, SA, 2007.

PIOVESAN, Flávia. Introdução ao sistema interamericano de proteção dos direitos humanos: a convenção americana de direito humanos. In: GOMES, Luiz Flávio; PIOVESAN, Flávia (Coord.). 0 sistema interamericano de proteção dos direitos humanos e o direito brasileiro. São Paulo: Revista dos Tribunais, 2000.

RAWLS. John. Justice as Fairness: a restatement. Cambridge: Harvard University Press, 2001.

RAWLS. John. Political Liberalism. New York. Columbia University Press, 2005.

RODOTÀ, Stefano. La vita e le regole: tra diritto e non diritto. Milão: Feltrinelli, 2006.

ROSS, W. D. The right and the Good. Oxford: Clarendon, 1930.

TEPEDINO, Gustavo; BARBOSA, Heloisa Helena; MORAES, Maria Celina Bodin. Código Civil Interpretado, conforme a Constituição da República, Volume 1: Parte Geral e Obrigações. $2^{\mathrm{a}}$ ed., rev. e atual. $1^{\text {a }}$ Tiragem, Rio de Janeiro: Renovar, 2011.

TESÓN, Inmaculada Vivas Tesón. Más allá capacidade de entender y querer... Um análisis de la figura italiana de la administración de apoyo y una de apoyo y una propuesta de reforma del sistema tuitivo español. Observatório Estatal de la Discapacidad. Olivenza: FUTUEX, 2012.

SCHALOCK, Robert L.; LUCKASSON, Ruth A.; SHOGREN, Karrie A. The Renaming of Mental Retardation: Understanding the Change to the Term Intellectual Disability. Intellectual and Developmental Disabilities, v. 45, n. 2, abr. 2007, p. 116-124.

SCHULZE, Marianne. Tomada de decisões: somente para quem está no poder? Revista Deficiência Intelectual - DI, ano 5, n. 8, jan./jun. 2015, p. 4-10.

STANZIONE, Pasquale. Capacità (diritto privato). In: AUTORINO, Gabriela; STANZIONE, Pasquale. Diritto civile e situazioni esistenziali. Torino: Giappichelli, 1997, p. 56.

UNITED NATIONS. General Assembly Human Rights Council (2009). Thematic Study by the Office of the United Nations High Commissioner for Human Rights on enhancing awareness and understanding of the Convention on the Rights of Persons with Disabilities, A/HRC/10/48, 26 January 2009, paragraph 43. 
UNITED NATIONS. Universal Declararion of Human Rights. 217 (III) A. Paris, 1948. Disponível em: <https://www.ohchr.org/EN/UDHR/Documents/UDHR_Translations/eng.pdf> Acesso em 30 ago 2018.

WEBER, Thadeu. A ideia de um mínimo existencial de J. Rawls. Kriterion, Revista de Filosofia, Belo Horizonte, nº 127, Jun./2013, p. 197-210.

XAVIER, Fernanda Dias. União Estável e Casamento: a impossibilidade de equiparação à luz dos princípios da igualdade e da liberdade. Dados eletrônicos. Brasília, TJDFT, 2015. Disponível em: <http://www.tjdft.jus.br/institucional/escola-de-administracao-judiciaria/planoinstrucional/e-books/e-books-pdf/uniao-estavel-e-casamento>. Acesso em: 30 abr. 2017.

\section{COMO FAZER A REFERÊNCIA DO ARTIGO (ABNT):}

SANTOS, Marcelo Pereira dos; HOGEMANN, Edna Raquel Rodrigues Santos. Pessoas com deficiência mental ou intelectual: um estudo sobre casamento e união estável na perspectiva da lei brasileira de inclusão. Revista Eletrônica do Curso de Direito da UFSM, Santa Maria, RS, v. 13, n. 3, p. 904-926, dez. 2018. ISSN 1981-3694. Disponível em: < https://periodicos.ufsm.br/revistadireito/article/view/30632 >. Acesso em: dia mês. ano. doi: http://dx.doi.org/10.5902/1981369430632. 